Open Access

\title{
A review of Lise Fontaine, Tom Bartlett and Gerard O'Grady (eds.), Systemic functional linguistics exploring choice. Cambridge: Cambridge University Press, 2013. 533pp
}

\author{
Changling Zhao ${ }^{1 *}$ (D) and Wei $\mathrm{He}^{2}$
}

* Correspondence: zhchlcr@163.com

${ }^{1}$ School of Foreign Studies, University of Science and

Technology Beijing, Beijing, China Full list of author information is available at the end of the article

\begin{abstract}
Systemic Functional Linguistics Exploring Choice provides a fresh inter-disciplinary perspective on the key notion of choice in Systemic Functional Linguistics (SFL). Although one of the basic assumptions of SFL is that language is a system of choices, the very nature and the place of choice have not been explicitly and critically debated within current SFL literature. With a critique of this as the point of departure, the editor Lise Fontaine points out in the introduction that the purpose of the volume is to open the debate on choice and offer a critical examination of its place in systemic functional theory. The volume comprises 22 chapters bringing together a range of linguistic viewpoints, informed by sociology, evolutionary theory, computational approaches, psychology and neuroscience to produce a comprehensive account of choice. It is divided into five sections, and each section addresses one of the five questions brought up by the editor.
\end{abstract}

The first section, "Choice: Theory and Debate", includes six chapters mainly discussing the concept of choice. Chapter 1 outlines Halliday's key contribution to the debate of choice (Halliday 1976). It is Halliday who firstly discusses the very nature and centrality of the notion of choice. According to Halliday, choice is the core mechanism for expressing meaning whose nature must be interpreted semiotically. In Halliday's view, all human and semiotic activities involve choice and "to mean is to act semiotically" (p.16) (Halliday 1978). On the whole, Halliday's discussion on the concept of choice is mainly from the perspective of sociology. Butt, Moore and Tuckwell, in the next chapter, extend Halliday's discussion in important ways from an evolutionary perspective. Drawing on the work of Sapir, Darwin and various biological views of selection, they propose the concept of motivated selection which refers to "those regularities that could not be rationally explained away as random, and whose effects in a semantic ensemble appear to constitute a convergence of diverse resources towards some recognisable end" (p.51). In order to examine the issues surrounding motivated selection, they make an analysis of clausal taxis to elucidate the choices that "the text 'recruits' to its purpose" (p.51). Chapter 3, by Freddi, examines the concept of choice in terms of paradigmatic and probabilistic views of language. Freddi argues that choice is a fundamental concept in understanding the relation between frequencies of occurrence and probabilities assigned

(c) The Author(s). 2017 Open Access This article is distributed under the terms of the Creative Commons Attribution 4.0 International License (http://creativecommons.org/licenses/by/4.0/), which permits unrestricted use, distribution, and reproduction in any medium, provided you give appropriate credit to the original author(s) and the source, provide a link to the Creative Commons license, and indicate if changes were made. 
in a system. She suggests that choice should be extended beyond paradigmatic relations to the syntagmatic axis of language. In Chapter 4, Bache raises questions on what a term in the system can or should be and where it comes from. In answering these questions, Bache undertakes an interpretation of the concept of choice. By using examples of the progressive/nonprogressive distinction in the English tense system, Bache offers a proposal for how features can be identified and how their systemic relation can be described. Bache suggests that any feature in a system should be communicatively motivated and satisfy higher-level communicative strategies. Similar to Freddi, in Chapter 5, Fontaine also bases her interpretation of choice on probabilities, but she offers an account of choice as process instead. Her view of choice as selection relies on an interpretation of the significance of probabilities in relation to systemic networks from a language processing perspective. Fontaine exploits the counterintuitive nature of probabilities to show how choice could serve a complex recursive function in terms of process. In the last chapter, Fawcett, like Bache, directly addresses the question of what the concept of choice is. He proposes that choice does not occur where the options are modelled. Fawcett claims that how speakers choose the features in the systemic network is handled by higher-level planning components referred to as 'microplanners' in computational linguistics. According to Fawcett, a microplanner is needed for each major area of meaning.

Section two, entitled "Cognitive and Neurolinguistic Views on Choice", seeks to answer the question about how choice contributes to linking language and cognition in three chapters. In Chapter 1, Lamb endeavours to bridge the intra-organism orientation and inter-organism orientation. By focusing on the nature of choice as portrayed in systemic networks but viewed from the perspective of relational networks, Lamb shows the neurocognitive linguistic theory can be related to SFL. He proposes a neurologically plausible justification for Halliday's original insight of choice in conceptualizing language structure in terms of paradigm. In the following chapter, Asp argues that meaning potential leaves us with paradoxes of unconscious choice and unintentional agents. She uses evidence from neurolinguistic imaging to develop a view that speakers act as agents who are not only capable but continuously making conscious choices in discourse. In the last chapter, Gil carries on Lamb's work and tests the extent to which choice can be seen to be neurologically plausible. Gil, in Chapter 3, interprets the transitivity and mood networks from a neurocognitive perspective and finds the differences between the nature of the two types of network: systemic networks classify meaning potential for social communication (inter-organism oriented) (Halliday 1985) whereas relational networks attempt to provide an operational model of the linguistic system of an individual (intra-organism). Gil concludes that more research is required to show how choice could be represented as operationally plausible.

Section Three, labelled "Linguistic Constraints on Choice", contains three chapters in which the concept of choice is explicitly theorized in relation to how it is constrained or enabled by language use. In the first chapter, Martínez-Insua examines how textual conditions affect the choice of existential there-constructions (TCs). She uses spoken and written data from late Middle English (LME) to Present-Day English (PDE) to investigate how the concepts of choice and choosing in relation to the textual condition may determine the appropriateness of TCs by considering their occurrence: (i) in a given context; (ii) with a given output (iii) at a given probability. Different from Martínez-Insua's 
micro-perspective, Thompson takes a macro-perspective to consider the effect of choice of conjunctives in the organization of political texts. He explores the different strategies employed by various contemporary political speakers to achieve persuasive effect and makes a distinction between choice as constraint and choice as freedom. O'Donnell adopts an integrated perspective in his 'Dynamic View of Choice in Writing: Composition as Text Evolution'. By drawing on computational and psycholinguistic approaches to explore linguistic choice, O'Donnell argues that the proper home of linguistic choice is in the process of production of the text rather than the text/product itself. He concludes that rhetorical structure theory has the greatest explanatory potential for text production and there are significant implications for the teaching of writing.

Section Four, called "Cultural and Contextual Constraints on Choice", consists of six chapters attempting to address the question of how choice can be defined or explained in relation to the contexts of situation and culture. In the first chapter, Hasan explores two facets of choice in language: choice in the system and choice in the process. In Hasan's view, choice is a central term that enables the analyst to enter into an explicit discourse on how language as a semiotic system becomes a powerful resource for the exchange of meanings in social contexts (Hasan 1995). In the following chapter, Urbach investigates how context of culture can motivate language choices. She uses the example of tense selection in news reporting of war to identify contextual pressures in register that seem to motivate the choice of tense. Bowcher, in chapter three, further develops the network of choices relevant to the system of material action within the contextual parameter of field. She concludes that keeping material action as a choice in field provides a means of outlining features which play a role in defining the nature of activity in situations involving language. Bartlett, in Chapter 3, continues the development of Bowcher, in contextual parameters and questions the suitability of modeling the contextual parameter of tenor with the concept of choice. He argues that it is the speakers' perceptions of non-contextual features of environment and how they can be accommodated into their world view that motivate choices in construing contexts. In Chapter 4, Berry completes the discussion of contextual parameters with her interpretation of choice in relation to mode. She analyzes choices in theme in the register of radio news and sports bulletins. Berry has identified a critical area of grammar that demands an account of the relationship between choice and context: the nature of theme selection and the role of referring in the overall model. In the last chapter, Castel discusses the genre constraints on the semantic options available in English from the perspective of computational linguistics. Using Fawcett's computational version of Cardiff Grammar, Castel shows how the notion of preference in relation to choice can be extended to capture genre-specific constraints.

Section Five, titled "Interpreting Choice", includes four chapters concerned with the study of choice in text. In the first chapter, Teich distinguishes three views of choice: choice-as-option, choice-as-result and choice-as-process (Matthiessen et al. 2010). In Chapter 2, Miller and Johnson present a methodology to overcome difficulties in evaluation analysis. They show speakers' choice in terms of evaluation and stance in institutional deliberative debate can be of a 'register-idiosyncratic' nature. In the next chapter, Kappagoda challenges the place of choice in characterizing and modeling linguistic behaviour. $\mathrm{He}$ argues that the concept of choice can be used as a gateway to understanding the complex systems of language and text. Lastly, Filho uses the evidence from his studies 
of interlanguage (hereafter IL) to determine whether SFL concept of choice can offer an explanation for fossilization. His analysis allows him to offer a description of the systemic continuum of written IL registers and an improved methodological approach to IL research in second language development.

Overall, the 22 chapters in this volume offer a thorough and varied examination of the central issue of choice in SFL from multi-disciplinary perspectives, which fills a fundamental gap within the SFL literature and can drive forward our understanding of choice in various important ways. Each section of the volume presents the works of scholars primarily addressing one of the key questions raised by the editors, yet various permutations and combinations of specific chapters can give us an enhanced view over any one chapter on its own. The broad-range and in-depth examination and debate of choice in this volume greatly extend and enrich Halliday's original insight of choice, which will create a common ground for further development of the underlying notion and have a far-reaching influence on SFL.

\section{Authors' contributions}

Both authors read and approved the final manuscript.

Competing interests

The authors declare that they have no competing interests.

Declaration

The authors of A Review of Lise Fontaine, Tom Bartlett and Gerard O'Grady (eds.), Systemic Functional Linguistics Exploring Choice declare that the present review is completed by ourselves without any reference to any other author except the original authors of the collection. Our main contribution is to recommend the valuable collection which explores deeply the essential notion of choice in systemic functional linguistics to those who are interested in the theories and applications of SFL. We express heartfelt gratitude to the reviewers of the present book review for their prompt reply and pertinent comments.

\section{Publisher's Note}

Springer Nature remains neutral with regard to jurisdictional claims in published maps and institutional affiliations.

\section{Author details}

${ }^{1}$ School of Foreign Studies, University of Science and Technology Beijing, Beijing, China. ${ }^{2}$ National Research Centre for Foreign Language Education, Beijing Foreign Studies University, Beijing, China.

\section{References}

Halliday, M.A.K. 1976. A brief sketch of systemic grammar. In Halliday: system and function in language. selected papers, ed. G. Kress, 3-6. London: Oxford University Press.

Halliday, M.A.K. 1978. Language as social semiotic: the social interpretation of language and meaning. London: Arnold.

Halliday, M.A.K. 1985. Language, context and text: aspects of language in a social-semiotic perspective. Geelong: Deakin University Press.

Hasan, R. 1995. The conception of context in text. In Discourse in society: systemic functional perspectives: meaning and choice in language: studies for Michael Halliday, ed. P. Fries and M. Gregory, 183-283. Norwood: Ablex.

Matthiessen, C., K. Teruya, and M. Lam. 2010. Key terms in systemic functional linguistics. London: Continuum.

\section{Submit your manuscript to a SpringerOpen ${ }^{\circ}$ journal and benefit from:}

- Convenient online submission

- Rigorous peer review

- Immediate publication on acceptance

- Open access: articles freely available online

- High visibility within the field

- Retaining the copyright to your article

Submit your next manuscript at $>$ springeropen.com 